\title{
O poder de compra estatal: elemento de fomento da sustentabilidade e da inovação
}

The state purchasing power: element of fostering sustainability and innovation

\author{
${ }^{1}$ Universidade Nove de Julho (UNINOVE), doutor, emaill: nabarreto2016@gmail.com
${ }^{2}$ Universidade Nove de Julho (UNINOVE), doutora, email: claudiabscirani@gmail.com
${ }^{3}$ Universidade de São Paulo (USP), doutor, email: alvair@ usp.br
}

Rodrigo Lopes Nabarreto ${ }^{1}$ (D) , Claudia Brito Silva Cirani ${ }^{2}$ (D) e Alvair Silveira Torres Júnior ${ }^{3}$

\section{RESUMO}

No novo contexto mundial, a inovação e a sustentabilidade têm um importante papel no desenvolvimento da sociedade. O Estado, atento a este aspecto, optou por fazer uso de seu poder de compra para fomentar o desenvolvimento sustentável e a inovação. Neste cenário, propusemos avaliar o panorama dos gastos públicos e do comportamento licitatório, a fim de identificar se, nos últimos anos (2012-2018), o poder de compra do Estado esteve direcionado ao desenvolvimento sustentável e à inovação. A realização deste trabalho justificou-se em virtude de uma lacuna na literatura com relação ao tema. Ao final, concluímos que o Estado tem focado seus recursos no fomento do desenvolvimento sustentável de forma considerada e na inovação de forma tímida, advindo desta política novas oportunidades de negócios para as empresas.

Palavras-chave: Inovação. Sustentabilidade. Poder de compra estatal.

\begin{abstract}
In the new global context, innovation and sustainability play an important role in the development of society. The State, in this regard, has opted to use its purchasing power to foster sustainable development and innovation. In this scenario, we proposed to evaluate the panorama of public expenditures and bidding behavior, in order to identify whether, in the last years (2012-2018), the purchasing power of the State was directed towards sustainable development and innovation. The accomplishment of this work was justified by virtue of a lacuna in the literature with respect to the subject. In the end, we conclude that the State has focused its resources on fostering sustainable development in a considered way and innovation in a timid way, resulting in this policy new business opportunities for companies.
\end{abstract}

Keywords: Innovation. Sustainability. Purchasing power of the state. 


\section{INTRODUÇÃO}

A questão ambiental é um assunto que gera reflexos em todos os países que compõem o globo terrestre. A racionalidade e as tecnologias dominantes geraram uma crise na civilização fomentando o início dessa discussão (CAMPOS, 1995). O impulso inicial de maior relevância desse tema deu-se com a Conferência Rio 92, cuja essência estava inspirada na diversidade e na igualdade das relações da sociedade e o combate à poluição, apoiando a preservação dos recursos naturais. $\mathrm{O}$ resultado de maior importância deste momento histórico foi conseguir mobilizar não só a sociedade civil, mas também a iniciativa privada. A preocupação em relação ao esgotamento dos recursos naturais tem sido crescente no decorrer das últimas décadas.

Uma das principais bandeiras levantadas na Rio92 defendia a necessidade de ampliação da eficiência no processo produtivo com o uso consciente das matérias-primas, evitando assim, a ocorrência de maiores impactos e danos ao meio ambiente. A Conferência das Nações Unidas sobre o Meio Ambiente e Desenvolvimento (CNUMAD) foi realizada em junho de 1992, na cidade do Rio de Janeiro e marcou a forma como a humanidade encarava sua relação com o planeta. Foi naquele momento que a comunidade política internacional admitiu claramente que era preciso conciliar o desenvolvimento socioeconômico com a utilização dos recursos da natureza.

A conscientização da sociedade pressionou a iniciativa privada a melhorar sua forma de atuar. Os processos produtivos foram modificados para se adequarem às questões ambientais, objetivando gerar menos impacto à natureza. Esse cenário propiciou condições favoráveis ao desenvolvimento de produtos e processos inovadores.

Foi a partir da CNUMAD que a expressão "desenvolvimento sustentável" começou a se tornar popular (BARBIERI et al, 2010). O movimento pelo desenvolvimento sustentável fomentou incontáveis iniciativas voluntárias, por parte de indivíduos e empresas, em prol do meio ambiente. Nesta mesma direção, o Estado passou a adotar uma postura ativa ao estabelecer políticas públicas específicas voltadas para o desenvolvimento sustentável. O uso do poder normativo estatal foi um dos instrumentos utilizados, visando alcançar os resultados esperados.

A Lei $n^{\circ}$ 12.349/2010, que alterou o artigo $3^{\circ}$ da Lei 8.666/1993 (Lei de Licitações e Contratos), estabeleceu que a licitação, dentre outras destinações, deveria promover o desenvolvimento nacional sustentável. Tratou-se de uma alteração legislativa significativa, já que

Ciências Sociais Aplicadas em Revista, v. 20, n. 38, p. 315-331, semestral, janeiro-junho, 2020. 
o Estado, motivado pela previsão legal, deveria passar a fazer uso do poder de compra para fomentar o desenvolvimento sustentável.

Em 2016, uma nova lei buscou fomentar o uso da inovação, também fazendo uso do poder de compra estatal. A Lei $\mathrm{n}^{\circ}$ 13.243, de 11 de janeiro de 2016, foi promulgada para dispor sobre estímulos ao desenvolvimento científico, à pesquisa, à capacitação científica e tecnológica e à inovação.

Destaca-se que a Nova Lei de Licitações e Contratações (Lei $n^{\circ} 14.133$, de $1^{\circ}$ de abril de 2021), manteve em seu artigo $5^{\circ}$ o desenvolvimento nacional sustentável como princípio basilar de orientação da aplicação da lei, demonstrando a grande importância dada a esta questão.

Como se nota, a legislação nacional estabeleceu como diretriz que as compras governamentais passassem a ter como norte a inovação e o desenvolvimento sustentável. Durante os anos de 2012 a 2018, os órgãos públicos federais, que compõem o Sistema Integrado de Serviços Gerais - SIASG gastaram mais de 350 bilhões de reais em processos de compra, conforme dados extraídos do Painel de Compras do Governo Federal. Desta forma, diante da considerável soma financeira, observa-se que o Estado tem plena condição de se valer de seu poder de compra para fomentar determinadas atividades, setores e políticas públicas.

\section{REFERENCIAL TEÓRICO}

Atualmente, o Governo Federal realiza suas compras por meio de um sistema eletrônico de compras governamentais denominado SIASG (Sistema Integrado de Administração dos Serviços Gerais). Trata-se de um instrumento criado com a finalidade de gerar eficiência nas compras públicas (FERNANDES, 2005). O desempenho do SIASG apresentou excelentes resultados, gerando benefícios diretos para a Administração Pública (SANTANA, 2013). O modelo de compras governamentais possibilita o exercício do poder de compra estatal. Assim, diante dos ditames e preceitos legais, o Estado deveria/poderia fomentar a inovação e o desenvolvimento sustentável por intermédio das compras realizadas diariamente.

Em face deste cenário, propôs-se, então, analisar o panorama dos gastos públicos e do comportamento licitatório, a fim de identificar se, no período compreendido entre os anos de 2012

Ciências Sociais Aplicadas em Revista, v. 20, n. 38, p. 315-331, semestral, janeiro-junho, 2020. 
a 2018, o poder de compra do Estado esteve, de fato, direcionado ao desenvolvimento sustentável e à inovação.

O desenvolvimento deste trabalho justifica-se em virtude de uma lacuna na literatura com relação ao poder de compra do estado e sua relação com a sustentabilidade e a inovação, especificamente no tocante aos gastos públicos realizados nos últimos anos.

Como contribuição, no que se refere ao aspecto descritivo exploratório, destaca-se a identificação do atual panorama de negociações estatais, em nível federal, propiciando, inclusive, a identificação de novas oportunidades de negócios e, no tocante ao acréscimo teórico, ressalta-se a ideia de uma embrionária proposta de elaboração de um indicador de desenvolvimento inovador sustentável, face à importância que será demonstrada no desenvolvido deste estudo.

A inovação constitui-se na implementação de um produto novo ou significativamente melhorado, de um processo, de um método de marketing, de um método organizacional nas práticas de negócios, na organização do local de trabalho ou nas relações externas (OECD, 2005). Não se trata de uma característica exclusiva dos setores de alta tecnologia, sendo acessível também aos setores tradicionais (CASSIOLATO \& LASTRES, 2000). O Estado, atento ao conceito e às características da inovação, passou a adotá-la como elemento norteador de suas ações, inclusive positivando-a em normas estratégicas. O que demonstra a importância deste instituto.

O conceito de sustentabilidade, comumente utilizado, surgiu na década de 1960, em resposta à preocupação com a degradação ambiental e a eqüidade social (MCKENZIE, 2004). O desenvolvimento sustentável busca atender às necessidades do presente sem comprometer a capacidade das gerações futuras poderem satisfazer suas próprias necessidades. Essas necessidades abrangem, prioritariamente, as essenciais dos pobres que habitam o mundo e as impostas pelo estado da tecnologia e organização social do ambiente daquele momento específico (WCED, 1987).

Novos estudos, inclusive, ressaltam a importância da discussão sobre a interpretação do conceito de sustentabilidade (BIELY et al, 2018). O Estado, cujo fim precípuo é a obtenção do bem comum (DALLARI, 2016), que se constitui no desenvolvimento integral do povo, conforme as peculiaridades estatais, em determinada época, por meio da criação de condições sociais que permitam a cada indivíduo e a cada grupo social alcançar seus respectivos fins particulares, deve atentar-se para a necessidade de se alcançar o desenvolvimento sustentável. 
Com as definições anteriormente mencionadas não se pretende trazer uma análise detalhada dos entendimentos existentes acerca de inovação e sustentabilidade, sendo certo que isso pode ser alcançado por outros meios (FRANCIS et al, 2005; TROTT, 2008; SHAFIA, 2016) e (HEDIGER, 1999; JABAREEN, 2008; QUENTAL, et al. 2011), trata-se de uma necessária breve introdução objetivando abalizar alguns conceitos para que se possa, com segurança, enfrentar à argumentação subsequente.

A Constituição Federal Brasileira, promulgada em 05 de outubro de 1998, traz em si o cerne do tratamento a ser dado às questões ambientais. O artigo 225 da Carta Magna positivou o desejo da sociedade ao estabelecer que todos têm direito ao meio ambiente ecologicamente equilibrado, bem de uso comum do povo e essencial à sadia qualidade de vida, impondo-se ao Poder Público e à coletividade o dever de defendê-lo e preservá-lo para as presentes e futuras gerações.

Faz-se importante mencionar que o direito previsto na primeira parte do artigo 225 da Constituição Federal refere-se não só à existência física, mas também à dignidade dessa existência, dependente de um meio ambiente sadio, sem o qual se pode dizer que a vida seria inviável. $\mathrm{O}$ Estado deve assegurar o acesso aos meios de sobrevivência a todos os indivíduos e todos os povos, evitando riscos ambientais capazes de comprometer a vida. O Governo deve envidar esforços para que isso ocorra.

Em 21 de junho de 1993 foi editada a Lei nº 8.666, que instituiu, dentre outras providências, normas para licitações e contratos da Administração Pública. Esta lei foi criada no intuito de regulamentar o inciso XXI do artigo 37 da Constituição Federal Brasileira que dispõe que as obras, serviços, compras e alienações do Estado serão contratados mediante processo de licitação pública que assegure igualdade de condições a todos os concorrentes.

Posteriormente, a Lei ${ }^{\circ} 12.349$, de 15 de dezembro de 2010, alterou o artigo $3^{\circ}$ da Lei $n^{\circ}$ 8.666/93, estabelecendo que a licitação destina-se a garantir a observância do princípio constitucional da isonomia, a seleção da proposta mais vantajosa para a administração e a promoção do desenvolvimento nacional sustentável e será processada e julgada em estrita conformidade com os princípios básicos da legalidade, da impessoalidade, da moralidade, da igualdade, da publicidade, da probidade administrativa, da vinculação ao instrumento convocatório, do julgamento objetivo e dos que lhes são correlatos. As inovações da Lei $\mathrm{n}^{\circ}$ 12.349/10 alteraram o regime geral de licitações e contratos administrativos para permitir a utilização do poder de compra do Estado como ferramenta de promoção do desenvolvimento sustentável brasileiro. Tratou-se de

Ciências Sociais Aplicadas em Revista, v. 20, n. 38, p. 315-331, semestral, janeiro-junho, 2020. 
uma mudança significativa no modelo de compras do Estado, pois no modelo anterior vigorava a eficiência das compras públicas, prevalecendo a ideia de comprar mais rápido e melhor pelo menor custo possível.

Recentemente, em $1^{\circ}$ de abril de 2021, foi editada a Lei $\mathrm{n}^{\circ} 14.133$, que, após quase três décadas, revogou a Lei 8.666, de 21 de junho de 1993, passando a reger as Licitações e Contratos Administrativos. Importante mencionar que o artigo 11 da referida norma legal estabeleceu que os processos licitatórios têm por objetivo incentivar a inovação e o desenvolvimento nacional sustentável.

Atualmente, com a nova política de compras, o Estado deve usar seu poder de compra para adquirir de segmentos estratégicos e relevantes para o desenvolvimento econômico e social sustentável. Este novo modelo tem como finalidade direcionar a demanda por bens e serviços do Estado para o desenvolvimento da economia local, micros e pequenas empresas e setores sensíveis da economia ou de interesse estratégico, gerando emprego e renda e primando pelo desenvolvimento econômico sustentável.

Neste mesmo sentido, recentemente, a Lei $\mathrm{n}^{\mathrm{o}}$ 10.973, de 02 de dezembro de 2004, que dispõe sobre incentivos à inovação e à pesquisa científica e tecnológica no ambiente produtivo, foi alterada pela Lei $\mathrm{n}^{\circ}$ 13.243, de 11 de janeiro de 2016. Uma das alterações de maior relevância foi a utilização do poder de compra do Estado para fomentar a inovação. Mostrou-se o fortalecimento desse instrumento.

O artigo 19 da Lei 10.973/2004, diante da alteração legislativa, passou a dispor que a União, os Estados, o Distrito Federal, os Municípios, as ICTs e suas agências de fomento promoverão e incentivarão a pesquisa e o desenvolvimento de produtos, serviços e processos inovadores em empresas brasileiras e em entidades brasileiras de direito privado sem fins lucrativos, mediante a concessão de recursos financeiros, humanos, materiais ou de infraestrutura a serem ajustados em instrumentos específicos e destinados a apoiar atividades de pesquisa, desenvolvimento e inovação, para atender às prioridades das políticas industrial e tecnológica nacional.

Como se pode notar, a legislação anteriormente invocada demonstra que o Estado está alerta à necessidade de fomentar a inovação e o desenvolvimento sustentável. Para tanto, dentre outros meios, o Estado elegeu seu poder de compra para atingir o objetivo proposto. O alinhamento da 
inovação com o desenvolvimento sustentável impulsionado pelo poder de compra estatal foi a estratégia estabelecida.

Os estudos sobre a utilização do poder de compra estatal não se tratam de algo recente (CAPUTO, 1978). Diversas são as perspectivas de análise (CASTELLBLANCH, 2003; TORRES, 2016; SILVA, 2016), dentre outros.

O poder de compra já foi objeto de estudo, inclusive, na saúde pública norte-americana (PURINGTON et al, 2011). Alguns estudos demonstram os principais sistemas de incentivos federais brasileiros disponíveis para o fomento da inovação (MARQUES, 2015) e analisam os processos de compras do governo federal (MOREIRA et al, 2017), entretanto, em nível nacional, quase nada foi escrito especificamente sobre o poder de compra estatal e sua relação com a inovação, o desenvolvimento sustentável e os gastos públicos efetivamente realizados.

A noção de sustentabilidade implica uma inter-relação necessária de justiça social, qualidade de vida, equilíbrio ambiental e a ruptura com o atual padrão de desenvolvimento (JACOBI, 1997). Nessa mesma direção a sustentabilidade nos negócios está ligada às preocupações éticas, envolvendo um compromisso com a justiça entre as gerações em questões de distribuição de riqueza, condições de trabalho e direitos humanos (BLOWFIELD, 2013; ELLIOTT, 2013). Atento, o Estado passa a atuar em consonância e em sintônia com estes relevantes aspectos.

Não é por acaso que o Estado optou por fomentar a sustentabilidade e a inovação por meio de seu poder de compra. Inovação e sustentabilidade estão relacionadas e podem propor uma série de benefícios para nossa sociedade. As inovações devem gerar resultados econômicos, sociais e ambientais positivos, contudo, deve haver uma sustentabilidade nesses resultados. Entretanto, esses resultados não são fáceis de serem alcançados, tampouco medidos, diante das incertezas que a inovação traz. Neste cenário, estudos envolvendo os possíveis impactos das inovações na sustentabilidade passam a ter importância fundamental (ALLEN et al, 2018).

Os efeitos econômicos podem ser previstos e medidos pelas empresas, contudo, os efeitos sociais e ambientais são mais difíceis de serem previamente avaliados (BARBIERI, 2010). Neste sentido, fazer uso do poder de compra do Estado aparenta ser um instrumento de alcance direto no desenvolvimento sustentável e na inovação.

As políticas públicas estabelecem diretrizes para que o Estado faça uso de outros instrumentos para fomentar o desenvolvimento sustentável e a inovação. O desenvolvimento 
sustentável exige a combinação de mudanças técnicas e sociais (SCHOT; GEELS, 2008). No arcabouço de medidas que podem ser tomadas pelo Estado, o poder de compra possibilita resultados imediatos e mudança de estratégias em curto lapso temporal.

Diversas ferramentas são desenvolvidas para se medir o desenvolvimento sustentável. Sistema indicador tem se constituído em um importante elemento legitimador na determinação da agenda pública e social para o desenvolvimento (BELLEN, 2006) Mas, talvez, com essa nova política pública adotada pelo Estado, inovação e sustentabilidade estejam, mais do que nunca, associadas. E essa associação poderá propiciar diversas oportunidades de negócios que surgirão da adoção de um novo critério de contratação pública baseado em soluções inovadoras e sustentáveis.

\section{METODOLOGIA}

Com o intuito de identificar o atual cenário de negociações sustentáveis onde o Estado, em nível federal, esteja envolvido na condição de adquirente, optou-se pela realização de uma pesquisa quantitativa, de caráter exploratório.

A pesquisa foi desenvolvida a partir de dados secundários adquiridos por meio de consulta ao Painel de Compras do Governo Federal, que se trata de uma ferramenta que apresenta os principais números das contratações públicas federais. O painel de compras, mantido pelo Ministério do Planejamento, apresenta dados estatísticos de licitações, atendendo ao princípio da transparência pública.

Para desenvolvimento da presente pesquisa, os dados existentes no Painel de Compras foram organizados, constituindo-se em uma série histórica de gastos públicos relativos ao período de janeiro de 2012 (data inicial dos dados) a dezembro de 2018.

Os dados foram extraídos do sítio https://www.comprasgovernamentais.gov.br/index.php/painel-de-compras-de-governo, que possibilita o acesso ao sistema "Painel de Compras do Governo". O sistema eletrônico permite a escolha dos dados de forma manual, gerando tabelas e relatórios.

Em uma primeira fase, os dados foram avaliados no sentido de se identificar eventual modificação no perfil gasto pelo Estado no decorrer do período, haja vista a promulgação da Lei $\mathrm{n}^{\circ}$ 12.349/2010, que estabeleceu que a licitação, dentre outras destinações, tinha como foco a promoção do desenvolvimento nacional sustentável. Em seguida, analisou-se o perfil dos gastos

Ciências Sociais Aplicadas em Revista, v. 20, n. 38, p. 315-331, semestral, janeiro-junho, 2020. 
públicos realizados com a aquisição de produtos sustentáveis. Em um terceiro momento, avaliouse se, com a promulgação da Lei $n^{\circ} 13.243$, realizada em 11 de janeiro de 2016, cujo objetivo foi fomentar a inovação por meio do poder de compra do Estado, ocorreu alguma mudança na conduta da Administração Pública no tocante ao valor total gasto com a aquisição de produtos e no tocante ao valor específico despendido com a aquisição de produtos sustentáveis. Para realização dessa análise a série histórica foi dividida em dois períodos: período A (janeiro de 2012 a dezembro de 2016) e período B (janeiro de 2016 a dezembro de 2018). Foram definidas, as seguintes hipóteses:

Hipótese 1 (H1) - A partir da promulgação da Lei n 12.349/2010 o Estado direcionou seu poder de compra ao desenvolvimento nacional sustentável, por meio da aquisição de produtos sustentáveis?

Hipótese 2 (H2) - A partir da promulgação da Lei nº 13.243/2016 o Estado direcionou seu poder de compra ao fomento da inovação?

\section{ANÁLISE DOS RESULTADOS}

O desenvolvimento da pesquisa possibilitou chegar a alguns resultados que se passa a expor, de forma especificada a seguir. Após a obtenção dos dados e aplicação das ferramentas estatísticas pode-se afirmar que a média do total dos gastos públicos federais, no período de 2012 a 2015, foi infimamente superior à média do período de 2016 a 2018.

Constata-se que, no período A, girou em torno de 4,8 bilhões de reais e, no período B, em torno de 4 bilhões de reais, ou seja, uma relativa diminuição nos valores gastos pela Administração Pública Federal.

No tocante aos valores gastos com produtos sustentáveis, observa-se que, no decorrer da série histórica, de 2012 a 2015, houve um gradual aumento nos valores despendidos pelo Estado na aquisição de produtos sustentáveis.

Esse aumento gradual não se confirmou no período de 2016 a 2018.

As tabelas a seguir expõem os resultados obtidos após a utilização de ferramentais estatísticos:

Ciências Sociais Aplicadas em Revista, v. 20, n. 38, p. 315-331, semestral, janeiro-junho, 2020. 
Tabela 1 - Valor total comprado antes da alteração

\section{VALOR TOTAL COMPRADO}

\begin{tabular}{cccccc}
$\begin{array}{c}\text { Antes da } \\
\text { alteração }\end{array}$ & Média & Mínimo & Máximo & DesvioPadrão & $\begin{array}{c}\text { Coeficientes } \\
\text { de variação de } \\
\text { Pearson } \\
\text { (DP/média) }\end{array}$ \\
\hline 2012 & $5.403 .023 .028,36$ & $1.493 .120 .330,76$ & $16.984 .917 .644,06$ & $5.219 .116 .815,44$ & 0.96596 \\
2013 & $4.283 .571 .618,93$ & $1.633 .900 .521,52$ & $9.353 .453 .020,50$ & $2.534 .470 .115,20$ & 0.59167 \\
2014 & $5.927 .582 .473,79$ & $2.193 .071 .447,27$ & $31.929 .188 .781,57$ & $8.357 .547 .528,85$ & 1.40994 \\
2015 & $3.641 .516 .362,60$ & $1.906 .760 .673,99$ & $7.368 .545 .099,80$ & $1.684 .447 .312,52$ & 0.46257 \\
\hline
\end{tabular}

Fonte: Dados da pesquisa.

Tabela 2 - Valor total comprado após a alteração

\begin{tabular}{cccccc}
\hline $\begin{array}{c}\text { Após a } \\
\text { alteração }\end{array}$ & Média & Mínimo & Máximo & DesvioPadrão & $\begin{array}{c}\text { Coeficientes } \\
\text { de variação de } \\
\text { Pearson } \\
\text { (DP/média) }\end{array}$ \\
\hline 2016 & $4.248 .182 .644,51$ & $2.120 .019 .437,18$ & $10.243 .935 .655,69$ & $2.477 .375 .383,00$ & 0.58316 \\
2017 & $3.910 .628 .522,68$ & $1.980 .885 .972,27$ & $8.816 .633 .944,64$ & $2,057,900,872.35$ & 0.5262 \\
2018 & $3.983 .868 .865,74$ & $2.092 .316 .659,15$ & $8.737 .747 .950,18$ & $1,872,243,192.93$ & 0.4699 \\
\hline
\end{tabular}

Fonte: Dados da pesquisa.

Tabela 3 - Itens sustentáveis antes da alteração

\section{ITENS SUSTENTÁVEIS}

\begin{tabular}{cccccc}
$\begin{array}{c}\text { Antes da } \\
\text { alteração }\end{array}$ & Média & Mínimo & Máximo & DesvioPadrão & $\begin{array}{c}\text { Coeficientes } \\
\text { de variação de } \\
\text { Pearson } \\
\text { (DP/média) }\end{array}$ \\
\hline 2012 & $1.907 .950,14$ & $485.205,65$ & $5.423 .942,44$ & $1.750 .463,68$ & 0.91746 \\
2013 & $2.366 .118,81$ & $386.015,25$ & $6.512 .764,72$ & $1.736 .258,51$ & 0.73380 \\
2014 & $2.760 .228,20$ & $563.334,95$ & $7.299 .701,15$ & $2.352 .405,44$ & 0.85225 \\
2015 & $10.689 .272,52$ & $513.287,68$ & $95.296 .618,99$ & $26.758 .753,70$ & 2.50332 \\
\hline
\end{tabular}

Fonte: Dados da pesquisa.

Tabela 4 - Itens sustentáveis após a alteração

\begin{tabular}{cccccc}
\hline $\begin{array}{c}\text { Após a } \\
\text { alteração }\end{array}$ & Média & Mínimo & Máximo & DesvioPadrão & $\begin{array}{c}\text { Coeficientes de } \\
\text { variação de } \\
\text { Pearson } \\
\text { (DP/média) }\end{array}$ \\
\hline 2016 & $31.331 .408,99$ & $977.029,98$ & $343.212 .501,56$ & $98.240 .592,89$ & 3.13553 \\
2017 & $14.590 .527,48$ & $371.026,50$ & $142.138 .819,91$ & $40,240,640.51$ & 2.75800 \\
2018 & $10.992 .735,38$ & $452.246,46$ & $101.793 .935,00$ & $28,703,754.86$ & 2.61120 \\
\hline
\end{tabular}

Fonte: Dados da pesquisa.

Ciências Sociais Aplicadas em Revista, v. 20, n. 38, p. 315-331, semestral, janeiro-junho, 2020. 


\subsection{SÉRIE HISTÓRICA}

No tocante aos valores gastos pela Administração Pública Federal, na aquisição de produtos, no período de 2012 a 2018, nota-se que, embora tenha ocorrido uma variação, entre 3 a 5 bilhões, não se pode tê-la como significante. Os dados colhidos apontam que houve uma oscilação nos gastos, contudo, sem grande discrepância.

Observa-se que, a média dos valores totais despendidos pela Administração Pública Federal na aquisição de produtos, no período de 2012 a 2015 e de 2016 a 2018, também não sofreram alterações significativas, o que demonstra que o perfil comportamental licitatório do Estado, no que se refere às compras, não se modificou.

Constata-se que os valores gastos pela Administração Pública, embora tenha uma pequena variação durante o período de 2012 a 2018, não demonstram que tenha ocorrido qualquer mudança de padrão no consumo estatal. E esse panorama mostra-se presente tanto quando se analisam os dados anualmente, quanto ao se analisarem os dados por meio de comparativo entre os períodos definidos (2012 a 2015 e de 2016 a 2018), uma vez que, embora exista oscilação, não se mostra significativa.

Por outro lado, no tocante aos valores gastos pela Administração Pública Federal, na aquisição de itens sustentáveis, no período de 2012 a 2018, nota-se que a variação mostrou-se significante, já que o valor variou entre 1,9 milhões e 31 milhões.

Destaca-se que, a média de gastos públicos, no período de 2012 a 2015 e de 2016 a 2018 , variou significativamente, o que comprova que o perfil comportamental licitatório do Estado, no que se referem às compras de itens sustentáveis, durante a vigência da Lei de Inovação, modificouse.

Ao analisar as médias de gastos públicos com produtos sustentáveis nos períodos A e B, observamos que houve um aumento significativo de 4,4 bilhões de reais para 18,9 bilhões de reais.

Durante o período de 2012 a 2015, os dados apontam que o Estado, efetivamente, direcionou seu poder de compra para o fomento da sustentabilidade, uma vez que, claramente, notase que os gastos com produtos sustentáveis cresceram ano a ano.

Ciências Sociais Aplicadas em Revista, v. 20, n. 38, p. 315-331, semestral, janeiro-junho, 2020. 
O ponto mais alto consubstanciou-se no ano de 2016, onde o Estado atingiu o pico de 31 milhões em gastos com itens sustentáveis.

Ao se levar em consideração a edição da Lei n ${ }^{\circ} 13.243 / 2016$, que também propiciou uma mudança de paradigma, ao direcionar o poder de compra do Estado para o fomento da Inovação, é possível verificar um aumento substancial nos gastos, mas mesmo com esses resultados não se têm evidências estatísticas significativas para afirmar que, a partir deste marco legal, o Estado passou a gastar mais com a Inovação.

Por outro lado com o cálculo do coeficiente de variação de Pearson, cujos valores são altos em toda a série histórica, há indícios estatísticos de que o processo de compras, no governo federal, sofreu interferências indeterminadas em cada exercício, sem clara tendência de comportamento, flutuando em torno da média com grande dispersão.

Nota-se que, a partir de 2015, há um salto no coeficiente de variação nos itens sustentáveis $(2,50)$, com patamar mais alto ainda de dispersão que se mantém em $2016(3,13), 2017(2,76)$ e $2018(2,61)$.

Estatisticamente, isso indica intervenções no processo, como sinal estatístico de um processo fora de controle, sem um padrão, o que pode configurar falta de consistência na forma em que os diversos gestores públicos estão respondendo às diretrizes da Lei.

O panorama demonstra que o Estado direcionou seu poder de compra ao desenvolvimento nacional sustentável por meio da aquisição de produtos sustentáveis, a partir da promulgação da Lei ${ }^{\circ}$ 12.349/2010. Contudo, a hipótese H1, confirmada pela média dos gastos em crescimento deve ser relativizada, aqui em função dessa grande variação que pode depender da ação da gestão pública em franca variação e, portanto, sem consistência.

Os dados obtidos apontam para um aumento significativo no volume dos gastos públicos em itens sustentáveis no decorrer dos anos, entretanto, o salto no coeficiente de variação indica a ausência de padrão.

Assim, H1 é confirmada parcialmente.

De outro lado, diante do cenário identificado, não se pode afirmar que o Estado tenha direcionado seu poder de compra ao fomento da inovação a partir da promulgação da Lei $\mathrm{n}^{\circ}$ $13.243 / 2016$.

Ciências Sociais Aplicadas em Revista, v. 20, n. 38, p. 315-331, semestral, janeiro-junho, 2020. 
Observa-se que o valor médio de compras do Estado no período A e no período B não apresenta significativa mudança de padrão. Fato que também ocorre ao se analisar os coeficientes de variação de Pearson.

Assim, a hipótese H2, por sua vez, evidencia-se não ser confirmada, uma vez que o valor médio e o coeficiente de Pearson já eram altos em 2015, antes da Lei de Inovação, não apresentando significativa alteração no padrão observado.

Ao se traçar um comparativo entre os períodos A e B, nota-se que houve um arrefecimento do pico ocorrido em 2016, data da promulgação da lei, voltando em 2017 e 2018 aos patamares de 2015. Assim, H2 não foi confirmada.

Por fim, destaca-se um importante achado, que se resume em uma possível relação entre o aumento de gastos públicos com itens sustentáveis e a edição da Lei no 13.243/2016.

Uma das possíveis maneiras de se investigar se, de fato, existiria essa relação seria analisar a natureza dos itens sustentáveis adquiridos pela Administração Pública Federal. Entretanto, ante a complexidade dos esforços necessários, fixa-se como sugestão para trabalhos futuros.

Uma primeira limitação é que o Painel de Compras aponta dados a partir de janeiro de 2012. A limitação poderá ser ultrapassada, em pesquisa futura, por meio da colheita de dados por meio da análise contábil de cada um dos órgãos que compõem o SISG (Sistema Integrado de Serviços Gerais). Com o afastamento desta limitação poderá ser analisada o perfil de compras anterior a Lei 12.349/2010, que direcionou o poder de compra estatal ao fomento do desenvolvimento sustentável.

Uma segunda limitação desta pesquisa é o tamanho da série histórica, em especial a partir da promulgação da Lei n ${ }^{\circ}$ 13.243/2016. A limitação poderá ser ultrapassada por uma série histórica maior. Com o afastamento desta limitação será possível uma melhor avaliação da hipótese H2.

\section{CONSIDERAÇÕES FINAIS}

Com o decorrer do tempo, as inovações crescem e se espalham por todos os setores, refletindo inclusive no estilo de vida das pessoas (ALLEN, et al, 2018) e influenciando organizações e sociedades por inteiro. As inovações trazem melhorias e desenvolvimento, entretanto, também produzem aspectos negativos. As inovações devem estar em consonância com o desenvolvimento sustentável nacional, a fim de maximizar sua importância social e econômica.

Ciências Sociais Aplicadas em Revista, v. 20, n. 38, p. 315-331, semestral, janeiro-junho, 2020. 
Atualmente, a inovação constitui-se um imperativo para o setor público, deixando de ser vista como uma mera oportunidade. Sua relevância é impar. Devendo ser alçada ao patamar de diretriz estatal.

A participação do Estado na busca pelo desenvolvimento sustentável também se mostra fundamental, seja através de algum estímulo por meio de estabelecimento de políticas públicas, seja por meio de ações diretas. Por outro lado, a ausência de políticas públicas tem o condão de retardar o desenvolvimento da sustentabilidade (ALLEN, et al, 2018). A fim de alcançar a sustentabilidade, as empresas e as partes interessadas, públicas e governamentais, precisam entender melhor os mecanismos subjacentes às práticas insustentáveis (KOPNINA, 2017).

A inovação e a sustentabilidade são de vital importância para o desenvolvimento da sociedade. Sob esta perspectiva o Estado tem a obrigação de contribuir para os seus fomentos. E, nesse sentido, o uso do poder de compra estatal vem contribuindo para essa evolução, mostrandose ser uma ferramenta vital.

A análise dos dados existentes no Portal de Compras da Administração Pública Federal apontou que o Estado tem focado seus recursos no fomento do desenvolvimento sustentável e menos relativamente à inovação, advindo desta política novas oportunidades de negócios às empresas, em especial motivada pela associação entre inovação e sustentabilidade, que poderá propiciar a adoção de um novo critério de contratação pública baseado em soluções inovadoras e sustentáveis.

Em que pese o aumento da média dos itens sustentáveis, o crescimento no coeficiente de variação, com valores muito altos nos anos de 2015 a 2018, indicam que a Lei de Inovação, sem um acompanhamento com métricas parciais e locais, pode perder seu impacto inicial em função de um processo fora de controle, que acabe direcionando o esforço de compras de itens sustentáveis para uma oscilação, diante de fatores indeterminados que o façam arrefecer e flutuar conforme setores ou gestores da Administração Pública.

A criação de um indicativo para dar clara tendência ao uso da Lei, baseado em complemento de métricas gerenciais locais e setoriais, aparente ser um caminho viável e importante para o desenvolvimento da sociedade.

O Estado tem que se atentar que inovar é colocar o novo em ação. Devem-se efetivar mudanças incrementais ou radicais, claro que sem deixar de se observar as características peculiares da Administração Pública.

Ciências Sociais Aplicadas em Revista, v. 20, n. 38, p. 315-331, semestral, janeiro-junho, 2020. 
O presente trabalho, ao analisar os dados públicos atinentes aos gastos estatais, em paralelo com as mudanças legislativas, aponta que o Estado, em suas dimensões executiva e legislativa, esta atento aos institutos da Inovação e Sustentabilidade. As constantes alterações na legislação indicam que o País entende a importância desses temas. Cabendo, então, ser mais efetivo na execução das diretrizes estabelecidas.

\section{REFERÊNCIAS}

ALlEN, P., ROBINSON, M., BUTANS, E. ET AL. Sustain Sci (2018). https://doi.org/10.1007/s11625-018-0593-y

ANDRADE, T. N. (2006). Aspectos sociais e tecnológicos das atividades de inovação. Lua Nova, 66(66), 139-166.

BARBIERI, J. C., Vasconcelos, I. F. G. de., Andreassi, T., Vasconcelos, F. C. de. (2010). Inovação e Sustentabilidade: Novos Modelos e Proposições. RAE-Revista de Administração de Empresas, $50(2), 146-154$.

BELLEN, Hans Michael Van. Indicadores de sustentabilidade: uma análise comparativa. São Paulo: FGV, 2006.

BIDERMAN, R., MACEDO, L. S. V. D., MONZONI, M., \& MAZON, R. (2008). Guia de compras públicas sustentáveis: uso do poder de compra do governo para a promoção do desenvolvimento sustentável. GVces.

BIELY, K., MAES, D. \& VAN PASSEL, S. Environ Dev Sustain (2018) 20: 223. https://doi.org/10.1007/s10668-016-9878-4

BOLTON, R., \& HANNON, M. (2016). Governing sustainability transitions through business model innovation: Towards a systems understanding.Research Policy,1731-1742.

BLOWFIELD, M. (2013). Business and sustainability. Oxford: Oxford University Press.

BURGELMAN, R. A., MAIDIQUE, M. A., \& WHEELWRIGHT, S. C. (1996). Strategic management of technology and innovation(Vol. 2). Chicago, IL: Irwin.

CAPUTO, D. (1978), State Purchasing power as an instrument for technological development, Buenos Aires: Centro de Investigaciones Sociales sobre el Estado y La Administracion

CARVALHO, I. A Invenção ecológica. Porto Alegre: Editora da UFRGS, 2001.

CASSIOLATO, J. E.; LASTRES, H. Sistemas de Inovação: políticas e perspectivas. Parcerias Estratégicas, n. 08, p. 237-255, 2000. 
CASTELLBLANCH, R. (2003). Challenging pharmaceutical industry political power in Maine and Vermont. Journal of Health Politics, Policy and Law, 28(1), 109-132.

DALLARI, D. Elementos de teoria geral do Estado. 33 ed. São Paulo: Saraiva. 2016.

Elliott, J. (2013). Introduction to sustainable development. New York: Routledge.

Engelman, R. (2013). Beyond sustainababble. In L. Starke (Ed.), State of the world 2013: Is sustainability still possible? Washington: Island Press.

FERNANDES, C. C. C. (2005). Abrangência, inserção e impacto transformador dos sistemas de compras eletrônicas na administração pública: análise do Siasg/Comprasnet. http://repositorio.enap.gov.br/bitstream/1/1543/1/2005\%20Vol.56,n.2\%20Fernandes.pdf

Francis, D., \& Bessant, J. (2005). Targeting innovation and implications for capability development. Technovation, 25(3), 171-183. doi:10.1016/j.technovation.2004.03.004

HEDIGER, W. (1999). Reconciling "weak" and "strong”' sustainability. International Journal of Social Economics, 26(7/8/9), 1120-1144. doi:10.1108/03068299910245859.

JABAREEN, Y. (2008). A new conceptual framework for sustainable development. Environment, Development and Sustainability, 10(2), 179-192. doi:10.1007/s10668-006-9058-z Kopnina, H. Environ Dev Sustain (2017) 19: 27. https://doi.org/10.1007/s10668-015-9723-1

JACOBI, P. (1997). Meio ambiente urbano e sustentabilidade: alguns elementos para a reflexão. In: CAVALCANTI, C. (org.). Meio ambiente, desenvolvimento sustentável e políticas públicas. São Paulo: Cortez, p.384-390.

LUNDVALL, B. Å. (Ed.). (2010). National systems of innovation: Toward a theory of innovation and interactive learning (Vol. 2). Anthem Press.

MARQUES, J. S., YIGITCANLAR, T., \& EDUARDO, M. D. C. (2015). Incentivizing innovation: a review of the Brazilian federal innovation support programs. Asia Pacific Journal of Innovation and Entrepreneurship, 9(1), 31-56.

MARTIN, C. J. (2016). The sharing economy: A pathway to sustainability or a nightmarish form of neoliberal capitalism?Ecological Economics,121, 149-159.

MCKENZIE, S. (2004). Social sustainability: Towards some definitions. Hawke research institute working paper series. http://www.unisa.edu.au/Documents/EASS/HRI/working-papers/wp27.pdf.

MENDONÇA, M. (2008). A política de inovação no Brasil e seus impactos sobre as estratégias de desenvolvimento tecnológico empresarial. Revista T\&C Amazônia, ano VI, (13), 29.

MOREIRA, P. A., GROTTA, R. C., \& JUNIOR, C. M. (2017). Compras Públicas Sustentáveis: Uma Análise Dos Processos De Compras Do Governo Federal Nos Últimos Cinco Anos. Latin American Journal of Business Management, 8(2).

NIDUMOLU, R., PRAHALAD, C. K., \&RANGASWAMI, M. R. (2009). Why sustainability is now the key driver of innovation.Harvard business review,87(9), 56-64. 
PURINGTON, K., GAUTHIER, A., PATEL, S., \& MILLER, C. (2011). On the road to better value: State roles in promoting accountable care organizations. The Commonwealth Fund and the National Academy for State Health Policy.

QUENTAL, N., LOURENC,O, J. M., \& DA SILVA, F. N. (2011). Sustainability: Characteristics and scientific roots. Environment, Development and Sustainability, 13(2), 257-276. doi:10.1007/s 10668-010-9260-x

RENNINGS, K. (2000). Redefining innovation-eco-innovation research and the contribution from ecological economics.Ecological economics,32(2), 319-332.

SANTANA, P. D. (2013). Sistema eletrônico de Compras Governamentais: o desempenho do SIASG-Comprasnet e sua influência para o futuro das compras governamentais.

SANTOS, R. M. T. (2011). Compras públicas sustentáveis: a utilização do poder de compra do Estado no fomento de produtos ecologicamente corretos na Fiocruz (Doctoral dissertation).

SCHOT, J; GEELS, F. W. (2008) Strategic niche management and sustainable innovation journeys: theory, findings, research agenda and policy. Technology Analysis \& Strategic Management, v. 20, n. 5 , p. 537-554.

SHAFIA, M. A., SHAVVALPOUR, S., HOSSEINI, M., \& HOSSEINI, R. (2016). Mediating effect of technological innovation capabilities between dynamic capabilities and competitiveness of research and technology organisations. Technology Analysis \& Strategic Management, 28(7), 116. doi:10.1080/09537325.2016.1158404

SILVA, R. A. (2016). ACORDO DE COMPENSAÇÃO (OFFSET) EM ITENS DE DEFESA: Uma perspectiva do setor aeronáutico DOI: http://dx. doi. org/10.18838/2318-8529/rdiet. v10n2p317-353. Revista de Direito Internacional Econômico e Tributário, 10(2 Jul/Dez), 317-353.

TORRES, R. L. (2016). A política de desenvolvimento da indústria farmacêutica brasileira de 2003 a 2014. Blucher Engineering Proceedings, 3(4), 74-83

TROTT, P. (2008). Innovation management and new product development. Harlow, UK: PrenticeHall.

WCED. (1987). Report of the World Commission on Environment and Development: Our common future. Retrieved from http://www.un-documents.net/our-common-future.pdf 